\title{
Editorial
}

Pensar en Movimiento:

Revista de Ciencias del Ejercicio y la Salud EISSN 1659-4436

Vol. $13, \mathrm{~N}^{\circ} 2$, pp. $1-2$

Cierre al 31 de diciembre de 2015

\section{LA INTERACCIÓN ENTRE AUTORES Y REVISORES}

¿Por qué naufraga un manuscrito? A lo largo de los años he participado en más de una docena de talleres y conferencias sobre cómo preparar un manuscrito para navegar exitosamente el proceso de publicación en revistas científicas. Cada vez aprendo cosas nuevas que trato de compartir con mis estudiantes de posgrado y mis colegas, pero he detectado que se dice muy poco sobre la interacción entre autores y revisores. Considero que se trata de una grave omisión, pues mi experiencia en el proceso de publicar mis propias investigaciones, así como de revisar las de otras personas, me ha permitido identificar varios elementos de esa relación donde fácilmente se hunde un manuscrito.

Para el investigador, cada revisor representa un obstáculo al final del largo camino que va desde concebir un estudio hasta publicarlo. Con demasiada frecuencia, los comentarios negativos de un revisor neutralizan las recomendaciones más moderadas o positivas de otro y acaban por inducir al editor a rechazar el envío. Algunas veces, esos comentarios negativos ponen en evidencia que la persona no entendió algún punto central del manuscrito. En lugar de molestarse con el revisor, es necesario cuestionarse por qué ocurrió el malentendido y hacer las modificaciones del caso antes del envío a otra revista. También, existe la opción de apoyarse en los comentarios del otro revisor para solicitar, respetuosamente, al editor que reconsidere su decisión o que envíe el documento a un revisor adicional, pero yo nunca he visto que esto dé resultado. La mejor opción, a pesar de ser la más dolorosa, es aprovechar los comentarios adjuntos al rechazo del manuscrito para mejorarlo antes del próximo envío.

Probablemente, la revista que rechazó su trabajo le había pedido sugerir revisores potenciales al inicio del proceso; tome en cuenta que no le conviene volver a recomendar a las mismas personas en un futuro envío a otra revista, pues usted no sabe si fue una de ellas quien lo calificó mal anteriormente.

Así son las cosas cuando el manuscrito es rechazado, pero hay otras posibilidades. El otro extremo, la aceptación inmediata sin correcciones, es sumamente inusual; en toda mi carrera científica solamente la he visto una vez. En el mejor de los casos, los autores 
tienen la oportunidad de corregir y reenviar su manuscrito. Ese proceso de corrección se debe hacer con tacto y con esmero para alcanzar la aceptación final, sin desanimarse por la complejidad y longitud de los comentarios. Se deben leer todas las observaciones de corrido y anotar los problemas principales. Luego se debe subrayar cada punto importante que requiera atención.

Entonces, se procede a hacer las modificaciones al manuscrito con algún método sistemático de control de cambios que facilite su identificación. Tanto al editor como a los revisores les ayuda tener una explicación clara de cómo se realizó cada uno de los cambios sugeridos, así como las explicaciones pertinentes cuando los autores no están de acuerdo con algún comentario específico. Es natural que el autor reaccione molesto ante algunas observaciones, pero debe evitar transmitirle su irritación al revisor, por ejemplo: en vez de responder "la variable dependiente ya estaba claramente definida en el manuscrito original en la p. 4" puede indicar "ahora se puede observar la definición de la variable dependiente en la p. 4".

Se puede ver el proceso de correcciones como una negociación entre los autores, que son quienes mejor conocen y entienden su propio trabajo, y los revisores, a quienes se debe ver como colaboradores que buscan mejorar la calidad del manuscrito, no como jueces que intentan condenarlo al rechazo. En esta negociación solamente hay una oportunidad: si el autor insiste demasiado en sus puntos y se muestra arrogante e inflexible, el rechazo es casi seguro. Pero si es demasiado complaciente se arriesga a publicar un manuscrito que no dice lo que quiso decir. Como autor, yo hago el esfuerzo por defender mi posición a la vez que hago sentir a cada revisor que estoy tomándome en serio sus observaciones. La decisión final del editor será el mejor indicador del éxito de su estrategia.

Quisiera concluir con dos comentarios importantes. En primer lugar, tenga siempre presente que el proceso de revisión por pares para publicación no es perfecto e involucra la idiosincrasia y circunstancias particulares tanto de los autores como de los revisores. En segundo, sepa valorar su trabajo: puede ser necesario reconocer que la investigación realizada tiene defectos graves que impiden su publicación, o quizás más bien deba perseverar hasta afinar bien el manuscrito y encontrar una revista cuyo editor y revisores sepan apreciar el producto de su labor, para llevarlo así a puerto seguro.

Luis Fernando Aragón V., Ph.D., FACSM

Director, PEnSAR En Movimiento

Universidad de Costa Rica

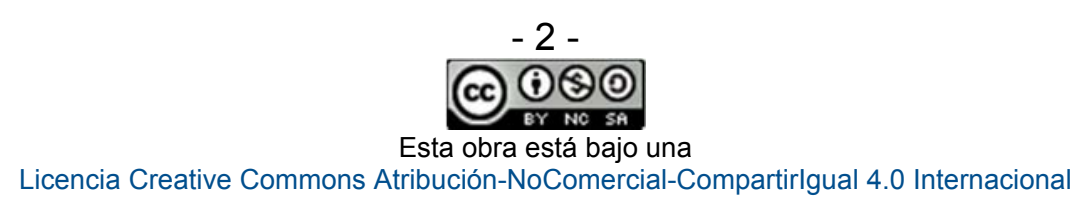

